\title{
Study of the effects of dietary polyunsaturated fatty acids: Molecular mechanisms involved in intestinal inflammation
}

\author{
By Bianca Knoch ${ }^{a, b}$, Matthew P.G. Barnett ${ }^{a}$, Nicole C. Roy and Warren C. McNabb ${ }^{a, k}$ \\ ${ }^{a}$ Food, Metabolism \& Microbiology Section, Food \& Textiles Group, AgResearch Grasslands, \\ Private Bag 11008, Tennent Drive, Palmerston North 4442, New Zealand \\ ${ }^{\mathrm{b}}$ Institute of Food, Nutrition \& Human Health, Massey University, Palmerston North 4442, New Zealand \\ * Corresponding author: warren.mcnabb @ agresearch.co.nz
}

\section{RESUMEN}

Estudio del efecto de los ácidos grasos poliinsaturados de la dieta: Mecanismos moleculares involucrados en la inflamación intestinal.

El uso de técnicas «omic» en combinación con sistemas modelo y herramientas moleculares nos permiten entender como los alimentos y sus componentes actúan en las rutas metabólicas que regulan los procesos transcripcionales. Los ácidos grasos poliinsaturados tienen efectos nutricionales y metabólicos diferenciadores porque producen una elevación de los productos regulados por lípidos y afectan a la expresión de varios genes involucrados en la inflamación intestinal. La presente revisión se enfoca en los efectos moleculares de los ácidos grasos poliinsaturados de la dieta en la inflamación intestinal.

PALABRAS CLAVE: Ácidos grasos poliinsaturados $n-3$ y n-6 de la dieta - Gen - Inflamación intestinal.

\section{SUMMARY}

Study of the effects of dietary polyunsaturated fatty acids: Molecular mechanisms involved in intestinal inflammation.

The use of "omics" techniques in combination with model systems and molecular tools allows to understand how foods and food components act on metabolic pathways to regulate transcriptional processes. Polyunsaturated fatty acids have distinctive nutritional and metabolic effects because they give rise to lipid mediated products and affect the expression of various genes involved in intestinal inflammation. The present review focuses on the molecular effects of dietary polyunsaturated fatty acids on intestinal inflammation.

KEY-WORDS: Dietary n-3 and n-6 polyunsaturated fatty acid - Gene - Intestinal inflammation.

\section{INTRODUCTION}

Traditional nutrition research has dealt with metabolic and physiological responses of the body to nutrients and has focussed on nutrient deficiencies in health and disease. Driven by the advances in molecular biology, biochemistry and genetics, nutrition research has more recently shifted its focus to genotype-based, personalised nutrition to maintain an individual's health and prevent diet-related diseases (Kussmann et al., 2006). The research field of gene-nutrient interactions investigates molecular effects of foods and food components with the use of "omics" technologies. These have the potential to define how nutrition influences metabolic and homeostatic pathways, how diet regulates genes in diet-related diseases and to what extent an individual's genetic background contributes to these diseases (Müller and Kersten, 2003; Bünger et al., 2007) or other phenotypes.

Chronic intestinal inflammation is a hallmark of Inflammatory Bowel Diseases (Crohn's Disease (CD) and Ulcerative Colitis (UC)), which together affect over 3.5 million people worldwide (Bassaganya-Riera and Hontecillas, 2006). Northern Europe and North America have reported the highest incidence rates and prevalence (Torres and Rios, 2008). CD is a condition for which genetic and dietary factors are known to predispose individuals (Podolsky et al., 2002), is immunologically mediated, and is characterized by destruction of the intestinal mucosa (BassaganyaRiera and Hontecillas, 2006). In New Zealand, 3075 new CD cases (representing the total number in the small and/or large intestine, and cases of unspecified or regional enteritis) have been registered from the last half of 2002 to the beginning of 2006. CD in the large intestine was more common with an increase of $16 \%$ (246 cases in $2005 / 06$ ) compared to the small intestine (180 cases in 2005/06). CD identified in both small and large intestine remained constant from 2002 to 2006, with approximately 140 new cases per year (New Zealand Health Information Service, 2007).

The use of "omics" technologies, together with a range of simplified model systems and molecular tools, allow us to better understand the basic molecular mechanisms of how foods and food components may ameliorate or prevent a phenotype, e.g. disease (Müller and Kersten, 2003). Accumulating evidence in humans and in animal models shows a beneficial effect of long-chain polyunsaturated fatty acids (PUFA), particularly n-3 PUFA, for a variety of inflammatory diseases (Stulnig, 2003), and these molecules may therefore prove to be of benefit for people with either UC or 
CD. n-3 PUFA have been shown to modulate the expression of genes that code for proteins involved in inflammation, lipid metabolism and energy utilization (Deckelbaum et al., 2006).

This review will provide an overview of the current knowledge on the effects of the two major classes of PUFA, n-3 and n-6 PUFA, on intestinal inflammation as determined using animal models and human studies. The mechanisms whereby $n-3$ and n-6 PUFA modulate gene expression involve multiple metabolic pathways and cross-talk between genes controlling lipid homeostasis, and the existing knowledge will be presented.

\section{POLYUNSATURATED FATTY ACIDS, INFLAMMATION AND IMMUNE RESPONSE}

PUFA modulate multiple processes including innate and acquired immunity, infectious pathologies due to bacteria and the course of chronic diseases such as inflammatory diseases (Calder, 2003; Mutch et al., 2005). The two major classes of PUFA, n-3 and n-6, are named after the first unsaturated carbon in the double bond. These two PUFA families, along with their precursors $\alpha$ linolenic acid (18:3n-3) and linoleic acid (18:2n-6), are essential and must be derived from the diet. Linoleic acid $(n-6)$ is the major PUFA in Westernized diets, followed by $\alpha$-linolenic acid $(n-3)$ (Schmitz and Ecker, 2008). The major sources of linoleic acid are vegetable oils such as corn, safflower, soybean and sunflower oil, whereas $\alpha$ linolenic acid can be mostly found in linseed oil, rapeseed, walnuts and blackcurrant oil, but also in dark green leafy plants (Dommels et al., 2002).

Linoleic acid and $\alpha$-linolenic acid are metabolized in mammalian cells by desaturase and elongation enzymes (Figure 1). Linoleic acid is converted to $\gamma$-linolenic acid and dihomo- $\gamma$ linolenic acid to form arachidonic acid (AA; 20:4n-6) (Schmitz and Ecker, 2008). AA is the major $n-6$ PUFA and dietary linoleic acid is the main source of tissue $A A$, although dietary $A A$ is also found in lean meats and meat fat (Dommels et al., 2002). The n3 fatty acid $\alpha$-linolenic acid is converted to stearidonic acid and eicosatetraenoic acid, then further converted to eicosapentaenoic acid (EPA; 20:5n-3) and docosahexaenoic acid (DHA, 22:6n-

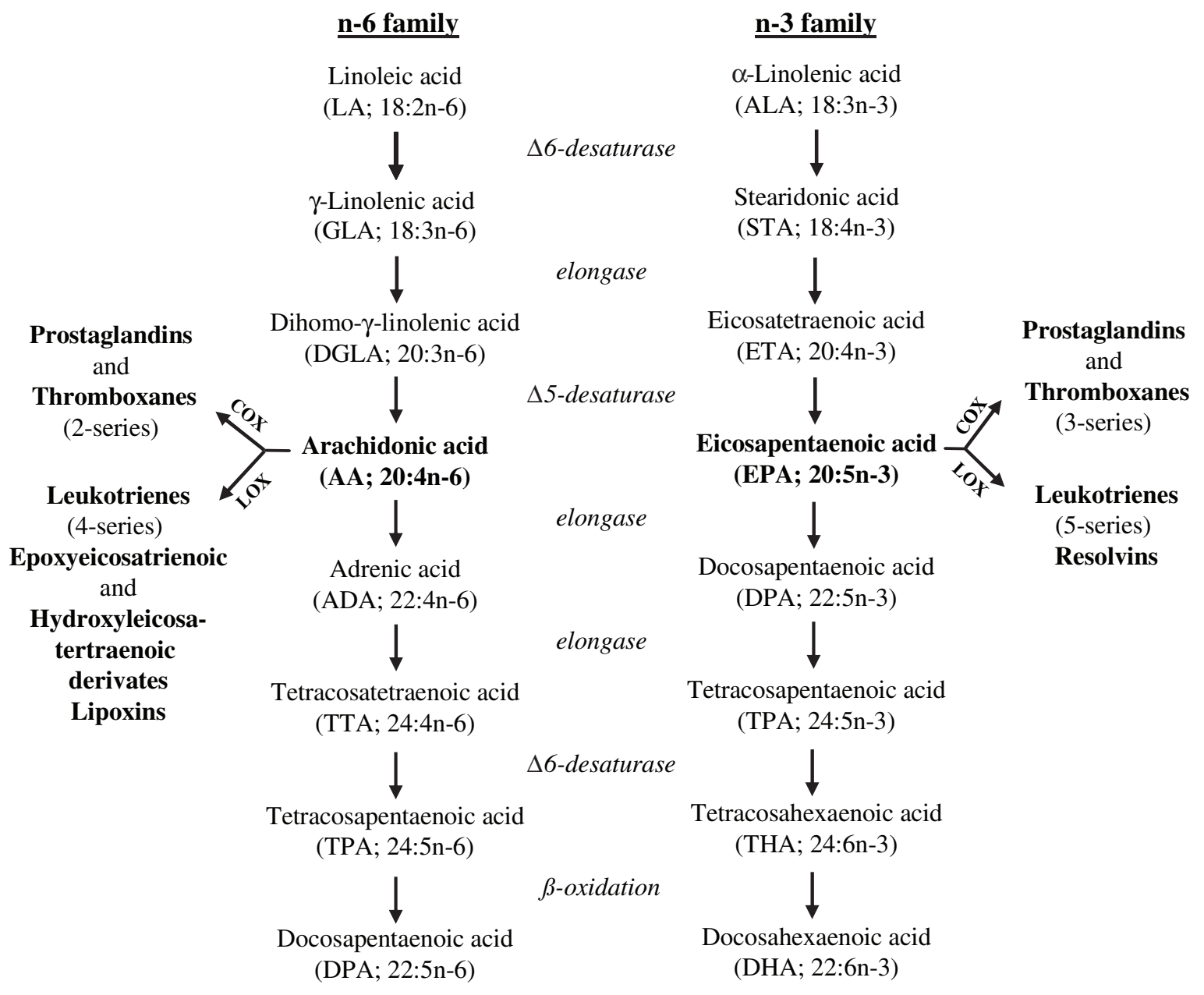

Figure 1

Metabolism of n-3 and n-6 PUFA (created from information in Mills et al., 2005 and Schmitz and Ecker, 2008). COX, cyclo-oxygenase; LOX, lipoxygenase. 
3). EPA and DHA are the major n-3 PUFA sources in marine fish such as salmon, tuna, herring, mackerel and anchovy (Dommels et al., 2002). AA and EPA can be further metabolized to more highly polyunsaturated fatty acids or activate a series of lipid mediators as shown in Figure 1 (Schmitz and Ecker, 2008).

\subsection{PUFA-derived mediators}

Inflammation and inflammatory responses are part of the normal, innate immune response as long as they occur in a controlled manner. Inappropriate inflammatory responses are characterized by upregulation of adhesion molecules and subsequent induction of leukocyte movement into sites of inflammation, production of inflammatory mediators and host tissue damage (Calder, 2006). Eicosanoids generated from 20-carbon PUFA (n-6) are the key link between PUFA and inflammation. Inflammatory cells usually contain high amounts of n-6 AA and low amounts of other 20-carbon PUFA such as EPA. High amounts of interleukins and the pro-inflammatory eicosanoids produced by $A A$ metabolism (and released from membrane phospholipids) have an important role in the early phase of inflammatory activation (Simopoulos, 2002; Calder, 2008). AA can be converted to series2 prostaglandins (PG) and thromboxanes (TX), series-4 leukotrienes (LT), to several hydroperoxyand hydroxy-eicosatetraenoic derivatives, and to lipoxins. Cyclo-oxygenases (COX) and lipoxygenases (LOX) are enzymes that catalyze these conversions (Figure 1). EPA is converted to series-3 PG and TX eicosanoids, series-5 LT, and to several hydroperoxy- and hydroxyeicosapentaenoic derivatives and resolvins.
Overall, mediators derived from EPA and DHA have anti-inflammatory properties while mediators formed from AA exert mostly pro-inflammatory or other metabolic effects (Table 1). These lipid mediators have been and are still studied in order to understand their pro- or anti-inflammatory actions (Bannenberg et al., 2007).

The theory that n-3 PUFA show antiinflammatory effects by competing with the incorporation of AA into membrane phospholipids, replacing it and thereby blocking the production of pro-inflammatory eicosanoids (especially $\mathrm{PGE}_{2}$ and $\mathrm{LTB}_{4}$ ), has long been established (Serhan and Chiang, 2008). The AA-derived $\mathrm{PGE}_{2}$ has anti- and pro-inflammatory modulation effects. It can induce COX2, and in this way induces its own synthesis and the production of the pro-inflammatory cytokine IL6 in macrophages. In contrast, $\mathrm{PGE}_{2}$ inhibits 5lipoxygenase to decrease the production of proinflammatory 4-series leukotrienes and can induce 15-lipoxygenase to form anti-inflammatory lipoxins (LX) (Schmitz and Ecker, 2008).

Lipoxins belong to a new family of PUFA-derived lipid mediators, including AA-derived aspirintriggered lipoxins; EPA-derived resolvin E-series (RvEs); DHA-derived resolvin D-series (RvDs) and protectins, which serve as endogenous agonists controlling inflammation by stimulating resolution (Serhan and Chiang, 2008). Bannenberg (2007) defined resolution as an essential part of the acute inflammatory response including the formation of pro- and anti-inflammatory and pro-resolution lipid mediators. These mediators serve as ligands to activate specific receptors and thus play an important role in the progression of the normal inflammatory response (Bannenberg et al., 2007; Serhan and Chiang, 2008). Resolution of

Table 1

n-3 and n-6 PUFA-derived lipid mediators and their metabolic effects

\begin{tabular}{|c|c|c|c|c|}
\hline Mediator effects & $\begin{array}{l}\text { AA (n-6)- } \\
\text { derived lipid } \\
\text { mediators }\end{array}$ & & $\begin{array}{l}\text { EPA (n-3)- } \\
\text { derived lipid } \\
\text { mediators }\end{array}$ & Mediator effects \\
\hline $\begin{array}{l}\text { Anti-inflammatory } \\
\text { Pro-inflammatory } \\
\text { Vasodilatation }\end{array}$ & $\begin{array}{l}\mathrm{PGD}_{2} \\
\mathrm{PGE}_{2} \\
\mathrm{PGF}_{2} \\
\mathrm{PGI}_{2}\end{array}$ & Prostaglandins & $\begin{array}{l}\mathrm{PGD}_{3} \\
\mathrm{PGE}_{3} \\
\mathrm{PGF}_{3} \\
\mathrm{PGI}_{3}\end{array}$ & $\begin{array}{l}\text { Less inflammatory } \\
\text { Anti-inflammatory }\end{array}$ \\
\hline $\begin{array}{l}\text { Pro-inflammatory } \\
\text { Vasoconstriction } \\
\text { Platelet } \\
\text { aggregation }\end{array}$ & $\begin{array}{l}\mathrm{TXA}_{2} \\
\mathrm{TXB}_{2}\end{array}$ & Thromboxanes & $\begin{array}{l}\mathrm{TXA}_{3} \\
\mathrm{TXB}_{3}\end{array}$ & $\begin{array}{l}\text { Less inflammatory } \\
\text { Vasodilatation } \\
\text { Weaker platelet } \\
\text { aggregation }\end{array}$ \\
\hline $\begin{array}{l}\text { Pro-inflammatory } \\
\text { Chemotaxis } \\
\text { of phagocytes }\end{array}$ & $\begin{array}{l}\mathrm{LTB}_{4} \\
\mathrm{LTC}_{4} \\
\mathrm{LTD}_{4} \\
\mathrm{LTE}_{4}\end{array}$ & Leukotrienes & $\begin{array}{l}\mathrm{LTB}_{5} \\
\mathrm{LTC}_{5} \\
\mathrm{LTD}_{5} \\
\mathrm{LTE}_{5}\end{array}$ & Less inflammatory \\
\hline \multirow[t]{2}{*}{$\begin{array}{l}\text { Anti-inflammatory } \\
\text { Pro-resolving }\end{array}$} & $\begin{array}{l}\mathrm{LXA}_{4} \\
\mathrm{LXB}_{4}\end{array}$ & Lipoxins & & \\
\hline & & Resolvins & $\begin{array}{l}\text { RvE1 } \\
\text { RvE2 }\end{array}$ & Anti-inflammatory \\
\hline
\end{tabular}


inflammation contributes to molecular events that remove inflammatory cells and restore tissue integrity (Bannenberg et al., 2007).

$\mathrm{LXA}_{4}$ exerts potent anti-inflammatory effects mediated through the activation of a specific Gprotein coupled lipoxin receptor and activates receptor-mediated molecular pathways to counterregulate acute inflammation (Bannenberg et al., 2007). Resolvins are oxygenated products derived from EPA and DHA and were first identified during the resolution phase of acute inflammation. The EPA-derived resolvin E1, shows anti-inflammatory actions by binding to a G-protein coupled receptor

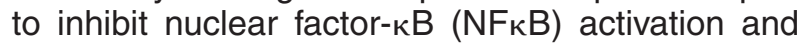
thus block the synthesis of pro-inflammatory cytokines and chemokines (Bannenberg et al., 2007, Schmitz and Ecker, 2008). RvE1 receptor is also expressed in gastrointestinal tissue (Bannenberg et al., 2007).

\subsection{Immunomodulatory mechanisms}

From early studies of patients with IBD a link between PUFA, the immune system and pathogenesis of CD was suggested. These studies reported decreased concentrations of $n-3$ PUFA in plasma phospholipids (Sheehan et al., 1992) and in adipose tissue (Geerling et al., 1999) and also decreased serum concentrations of total n-3 PUFA in IBD patients compared with control patients (Kuroki et al., 1997). The loss of n-3 PUFA increases the $n-6: n-3$ ratio, which implies the production of more pro-inflammatory eicosanoids.

Several aspects of the immunomodulatory effects of PUFA in intestinal inflammation have recently been investigated, e.g. the role of PUFA in modulation of pro- and anti-inflammatory eicosanoids, membrane fluidity, signal transduction, antigen presentation, gene expression and gastrointestinal flora (Mills et al., 2005). Mills et al., (2005) reviewed studies in humans and animals which reported that dietary n-3-rich fish oil supplementation decreased $A A$ levels in the membrane as AA was replaced by $n-3$ PUFA. As a result of the competitive inhibition of $A A$ metabolism, less pro-inflammatory eicosanoids are produced by AA. Immune cells, such as macrophages, are the main source of eicosanoids. Prostaglandins, for example, can suppress $T$ lymphocyte proliferation, $\mathrm{T}$ cell-mediated toxicity, IL2 production and natural killer cell activity in vitro (Goodwin and Ceuppens, 1983). Thus eicosanoids act directly on immune cells and are modulated themselves by PUFA (Mills et al., 2005).

PUFA have an important role in membrane structure. Incorporation of PUFA into membrane lipids increases membrane fluidity and affects the conformation of membrane protein complexes. Some membrane-bound enzymes and receptors are sensitive to the particular fatty acids that surround them (Mills et al., 2005). There are also membrane regions (the so-called lipid rafts) containing cholesterol, sphingolipids and signalling molecules, where signalling events can take place (Stulnig, 2003; Mills et al., 2005). Dietary n-3 PUFA are able to decrease the sphingomyelin content of lipid rafts in vivo. Displacement of acylated proteins from membrane lipid rafts is seen with EPA but to a lesser extent with $A A$ and could be due to altered protein acylation after PUFA incorporation or changes in lipid raft composition (Stulnig, 2003).

PUFA are involved in many intracellular signal transduction pathways in immune cells, specifically in $\mathrm{T}$ and B-lymphocytes. Long chain fatty acids can modulate signalling pathways and target gene expression by reciprocal modulation of the activation of Toll-like receptor 4 (TLR4) and its downstream signalling pathways. They suppress $\mathrm{NF}_{\kappa} \mathrm{B}$ activation and COX2 expression that are inducible by a TLR2 agonist in macrophages. Different types of fatty acids modulate different TLR molecules, suggesting a modulatory role for dietary fatty acids in immune and inflammatory responses by TLR activation in the intestine. Changes in dietary fat composition could modulate signalling pathways downstream of TLR molecules, as well as targeting gene expression and subsequent cellular responses (Mills et al., 2005).

In vitro and in vivo experiments suggest that the immunomodulatory mechanism of $n-3$ PUFA might occur via modulation of antigen-presenting cell function. Fish oil supplementation to healthy volunteers decreased the expression of membranebound MHC II antigen-presenting molecules in peripheral blood monocytes. Furthermore, a role for PUFA in modulating antigen-presenting cell function is supported by the observation that the expression of adhesion molecules such as intercellular adhesion molecule 1 (ICAM1) is down-regulated by n-3 PUFA. Adhesion molecule expression enables the antigen bearing cells in circulation to reach lymphoid areas to present antigen to $\mathrm{T}$ lymphocytes and stimulate an immune response (Mills et al., 2005).

Mucosal inflammation in IBD results from an inappropriate inflammatory response to microbiota in the intestine. TLR molecules are involved in the recognition of and the response to commensal microbiota or to pathogens, acting as pattern recognition receptors (Mills et al, 2005; Niess and Reinecker, 2006). It has been shown that intestinal microbiota play an important role in human colitis; reduced levels of Bifidobacteria have been observed in patients with CD (Favier et al., 1997). PUFA may affect the composition of the intestinal microbiota and thus alter the balance of inflammation in the intestine. It is suggested that dietary PUFA affect mucosal adhesion sites for gastrointestinal bacteria (e.g. Lactobacilli) (Kankaanpää et al., 2001) by altering the composition of the intestinal wall (Mills et al., 2005). This implies that dietary PUFA could enhance the functions of probiotic bacteria in the gastrointestinal tract, e.g. by stimulating adhesion (Mills et al., 2005; Torres and Ríos, 2008). 
Immune responses in IBD patients are triggered by the presence of commensal intestinal bacteria (Ewaschuk and Dieleman, 2006). Most animal models of IBD (such as IL10 gene-deficient mice and HLA-B27 transgenic rats) fail to develop chronic intestinal inflammation when raised in germ-free conditions (Taurog et al., 1994; Sellon et al., 1998). Enterococcus faecalis is a commensal bacterium of the intestinal microbiota and has been used to induce colitis in IL10 gene-deficient mice, both as a single defined strain (Balish and Warner, 2002) and in a combined inoculum with complex intestinal flora (Roy et al., 2007). It would therefore seem that the balance between beneficial and aggressive intestinal bacteria is an important factor which can influence the transition from mucosal homeostasis to chronic inflammation (Ewaschuk and Dieleman, 2006).

\section{POLYUNSATURATED FATTY ACID REGULATION OF GENE EXPRESSION IN IBD}

Long chain fatty acids have been known to contribute to enterocyte function and pathology (Heimerl et al., 2006). In particular, long chain n-3 and n-6 PUFA are incorporated into biological membranes and regulate such processes as energy metabolism, eicosanoid production, signal transduction and regulation of gene expression (Mutch et al., 2005; Deckelbaum et al., 2006). N-3 PUFA modulate the expression of genes that code for proteins involved in inflammation, lipid metabolism and energy utilization in several tissues and organs. They reduce inflammation and induce lipid oxidation for enhanced energy utilization (Deckelbaum et al., 2006). Long chain PUFA modulate inflammatory processes by altering fatty acid metabolism in the intestinal epithelial cells (Belluzzi, 2002). There are multiple mechanisms whereby long chain PUFA, especially n-3 PUFA, can affect transcription factor-dependent gene expression, the expression of nuclear hormone receptors and lipid second messengers. The latter activate other genes or other cellular events which affect gene expression, e.g. production of $n-3$ metabolites and subsequent gene expression (Deckelbaum et al., 2006).

\subsection{Fatty acid metabolism}

It has been shown that the altered expression of genes involved in fatty acid metabolism in IBD may be a consequence of inflammation, but may also contribute to IBD pathophysiology. Genes involved in uptake and activation of fatty acids include fatty acid transport proteins (FATP, solute carrier family 27), fatty acid binding proteins (FABP) and long chain acyl-CoA synthases (ACSL) (Heimerl et al., 2006).

The FATP transmembrane proteins in the intestinal membrane increase the uptake of long chain PUFA into cells and FATP gene expression levels directly correlate with long chain PUFA uptake. Six FATP proteins have been found in all fatty acid-metabolizing tissues of the human body (Stahl, 2004). High expression levels of FATP2 and FATP4 transporter genes have been found in ileum and colon tissues of healthy patients. In the colon of CD and UC patients, FATP4 gene expression was down-regulated compared to control tissues (Heimerl et al, 2006).

Other types of proteins (CD36 molecule, FABP and ACSL) can facilitate the uptake of PUFA. It is suggested that long chain PUFA either bind directly to FATP complexes, or bind first to CD36 which then releases the PUFA to FATP. Considerable amounts of CD36 mRNA were observed in healthy intestinal biopsies (Heimerl, 2006). A study with CD36deficient mice suggested only a minor role for CD36 in the lipid absorption in enterocytes (Goudriaan et al., 2002).

The cytoplasmic protein FABP binds PUFA inside the cell for further fatty acid metabolism. Only three of the seven FABP members described to date (FABP1, FABP2 and FABP6) have major roles in the intestinal tissue. High mRNA levels have been detected in ileum (FABP1, FABP2 and FABP6) and colon (FABP1 and FABP2) biopsies. The expression of FABP2 and FABP6 genes was down-regulated in colon of UC patients (Heimerl et al., 2006). FABP has also been considered as a plasma marker of intestinal injury in patients with UC, as the serum concentration of intestinal FABP was elevated in these patients and may indicate ileitis (WiercinskaDrapalo, 2008).

For the next step in fatty acid metabolism, acetylation of long chain fatty acids by ACSL is required. ACSL are integral membrane proteins with active sites facing the cytosol. Five human ACSL genes and several isoforms have been identified (Heimerl et al., 2006; Soupene and Kuypers, 2008). mRNA levels of ACSL1 and ACSL4 were found to be increased in ileum and colon of IBD patients. The ACSL1 and ACSL4 isoforms provide acyl-CoA for the synthesis of triacylglycerol and phospholipid; the latter of which might be incorporated into the intestinal membrane to maintain epithelial barrier function. Therefore, an up-regulation of some ACSL members by the fatty acids present in the enterocyte could support membrane integrity and decelerate the course of inflammation in IBD (Heimerl et al., 2006).

Inside the cytoplasm, fatty acids can be elongated and desaturated by specific elongases and desaturases, $\beta$-oxidized in mitochondria or peroxisomes for energy production, $\omega$-oxidized in microsomes, peroxidized, involved in membrane phospholipid or eicosanoid (PG, LT and TX) synthesis (Dulpus et al., 2000). PUFA are able to down-regulate the expression of genes for enzymes involved in fatty acid synthesis, including acetylCoA carboxylase, fatty acid synthase and stearoylCoA desaturase (Salter and Tarling, 2007). 


\subsection{Transcription factors}

Dietary PUFA can also directly regulate gene expression by interaction with transcription factors to exert their effects on various metabolic states in health and disease (Salter and Tarling, 2007). Transcription factors play an important role in IBD (Heimerl et al., 2006; Sanderson et al., 2008), for example $\mathrm{NF} K \mathrm{~B}$ in regulating production and activation of pro-inflammatory cytokines (Mitsuyama et al., 2001). Nuclear receptors, a family of ligand-activated transcription factors, are most relevant in mediating the effect of nutrients and their metabolites on gene transcription (De Vogel-van den Bosch, 2008) and can directly or indirectly regulate genes of lipid metabolism and inflammatory signalling (Schmitz and Ecker, 2008). Nuclear receptors that regulate PUFA-induced gene expression include peroxisome proliferatoractivated receptors (PPAR, NR1C), liver $X$ receptor (LXR, NR1H), retinoid $X$ receptor (RXR, NR2B), hepatocyte nuclear factor 4 (HNF4), farnesoid $X$ receptor (FXR, NR1H) and pregnane $X$ receptor (PXR, NR1I) (Heimerl et al., 2006; Salter and Tarling, 2007; Sanderson et al., 2008). Transcriptional regulation by these nuclear receptors requires heterodimerization with RXR. Receptors that also mediate effects of dietary fatty acids on gene expression include the transcription factors SREBP1 and NFKB (Sanderson et al., 2008). The interaction of PUFA with all of these transcription factors in the regulation of fatty acid metabolism genes is still illdefined in vivo.

PPAR can be activated by a range of natural and synthetic compounds, including fibrates, xenobiotics, and both saturated and unsaturated fatty acids (Salter and Tarling, 2007). PPAR isoforms, which belong to the steroid hormone nuclear receptor superfamily of ligand-activated transcription factors (which includes retinoic acid receptor (RAR), LXR and RXR), are particularly relevant to dietary fatty acid effects on gene expression. Three different isoforms of PPAR (PPAR $\alpha$ (NR1C1), PPAR $\beta$ (also known as $\delta$ ) (NR1C2), and PPARy (NR1C3)) have been characterized (Sampath and Ntambi, 2005; Bünger et al., 2007).

$\mathrm{N}-3$ and $\mathrm{n}-6$ PUFA serve as endogenous ligands for all PPAR isoforms with varying affinity for the receptor subtypes (Salter and Tarling, 2007). Furthermore, transactivation and competitive binding assays have revealed that PUFA metabolites, such as the naturally occurring eicosanoids, can also activate PPAR isoforms with greater affinity than their parent compounds (Sampath and Ntambi, 2005). N-3 PUFA are more potent activators of PPAR $\alpha$ than n-6 PUFA. After activation by a ligand, PPAR dimerize with RXR and the PPAR/RXR heterodimer binds to DNA response elements, called the PPAR response element, in the promoter of target genes (Sampath and Ntambi, 2005; Salter and Tarling, 2007).
PPAR $\alpha$ is the main PPAR isoform involved in regulation of genes of lipid and carbohydrate metabolism in hepatocytes (Sampath and Ntambi, 2005). PPAR $\alpha$ has been shown to be highly expressed in the small intestine (Bünger et al., 2007). PPAR $\alpha$ is also expressed in kidney, whereas PPAR $\gamma$ (subforms $\gamma 1, \gamma 2$ and $\gamma 3$ arising from alternative splicing of one gene) is mainly expressed in adipose tissue and macrophages (Salter and Tarling, 2007). PPAR $\beta$ is ubiquitously expressed (Salter and Tarling, 2007). PPAR $\alpha$ is associated with transcriptional up-regulation of the expression of genes involved in fatty acid oxidation and lipoprotein metabolism, including acyl-CoA oxidase, FATP, carnitine palmitoyl transferase 1, lipoprotein lipase and apolipoproteins AI and CIII. PPAR $\alpha$ inhibits the expression of genes encoding for pro-inflammatory proteins, including vascular cell adhesion molecule 1 (a membrane protein that mediates leukocyte extravasion to sites of tissue inflammation (Wu, 2007)) and interleukin 6, in the vascular endothelium (Salter and Tarling, 2007). There is some evidence that PUFA inhibit lipogenic gene expression by repression of SREBP mRNA (Sampath and Ntambi, 2005).

SREBP belong to the membrane-bound members of the basic helix-loop-helix leucine zipper family of transcription factors that were first characterized by binding to a sterol response element found on genes involved in cholesterolgenesis. Three isoforms of SREBP have been identified; SREBP1a and 1c, which regulate the expression of genes involved in fatty acid and cholesterol synthesis pathways, and SREBP2, which controls genes important for cholesterol homeostasis (Sampath and Ntambi, 2005; Salter and Tarling, 2007). The inactive precursor form of SREBP is located in the endoplasmic reticulum, linked to SREBP cleavage-activating protein (SCAP). With low sterol concentrations in the cell, SCAP moves with the SREBP to the Golgi apparatus where the active mature form of SREBP is released. The mature SREBP migrates to the nucleus and can bind to the sterol response element in the promoter region of target genes involved in cholesterol, triglyceride and fatty acid synthesis. When cellular sterol concentrations are high, sterol interacts with the protein Insig, an endoplasmic reticulum anchor protein, on the SREBP-SCAP complex and SREBP maturation is inhibited. As a consequence the transcription of target genes involved in lipid and lipoprotein metabolism is down-regulated (Sampath and Ntambi, 2005; Salter and Tarling, 2007).

SREBP1 expression is mainly regulated at the level of gene transcription, whereas SREBP2 expression is mainly regulated at a posttranslational level, through modulation of cleavage of its membrane-bound precursor to release the active nuclear form (Salter and Tarling, 2007). As reviewed by these authors, PUFA regulate SREBP expression partly through LXR. PUFA can inhibit 
the interaction of oxysterol ligands with LXR and thus inhibit activation of SREBP1c gene transcription by LXR. Another possible mechanism is the inhibition of LXR transcriptional activity by PUFA activation of PPAR. Increased competition between PPAR and LXR for the connection with its transcriptional partner $\mathrm{RXR}$ has been reported (Salter and Tarling, 2007). The effect of dietary PUFA on cell lipid homeostasis is a result of complex, controlled interactions between SREBP, PPAR, LXR and RXR transcription factors (Sampath and Ntambi, 2005; Deckelbaum et al., 2006; Salter and Tarling, 2007). An overview of PUFA and its influence on transcription factors is presented in Figure 2.

There is also evidence that n-3 PUFA affect $\mathrm{HNF} 4 \alpha$ transcriptional activity and exert hypotriglyceridemic effects. The HNF $4 \alpha$ gene is highly expressed in liver, but is also found in kidney, intestine and pancreas. This transcription factor is associated with the expression of genes involved in lipid and lipoprotein metabolism, such as apolipoproteins AII, AIV, CII and CIII, the microsomal triglyceride transfer protein, and cytochrome P450, family 7 , subfamily $A$, polypeptide 1 (CYP7A1). HNF $4 \alpha$ binds with high affinity to unsaturated longchain fatty acyl CoA which in turn inhibits HNF-4a transcriptional activity. HNF $4 \alpha$ binds to direct repeat 1 response elements as a homodimer and can compete with PPAR/RXR heterodimers for DNA binding (Salter and Tarling, 2007).

Another mechanism of PUFA-mediated gene expression is the regulation of the transcription factor $N F_{\kappa} B$. NF $\mathrm{NB}_{\mathrm{B}}$ and Inhibitor $\kappa \mathrm{B}\left(\mathrm{I}_{\kappa} \mathrm{B}\right)$ are colocated in the cytoplasm of cells as an inactive heterodimer. When $I_{\kappa} B$ is phosphorylated, $N F_{\kappa} B$ separates from $I_{\kappa} B$ and translocates to the nucleus to influence the transcription of a variety of proinflammatory genes, such as COX2 and IL6. AA stimulates NFKB translocation and thus induces $\mathrm{NF}_{\kappa} \mathrm{B}$ target gene transcription, whereas EPA inhibits translocation by PPAR $\alpha$-mediated activation, resulting in inhibition of the transcription of NFKB target genes (Sampath and Ntambi, 2005).

\section{A MOLECULAR APPROACH TO STUDY POLYUNSATURATED FATTY ACID-REGULATED GENES IN INTESTINAL INFLAMMATION}

An approach to define the molecular mechanisms whereby dietary PUFA alter intestinal inflammation is to identify PUFA-regulated genes

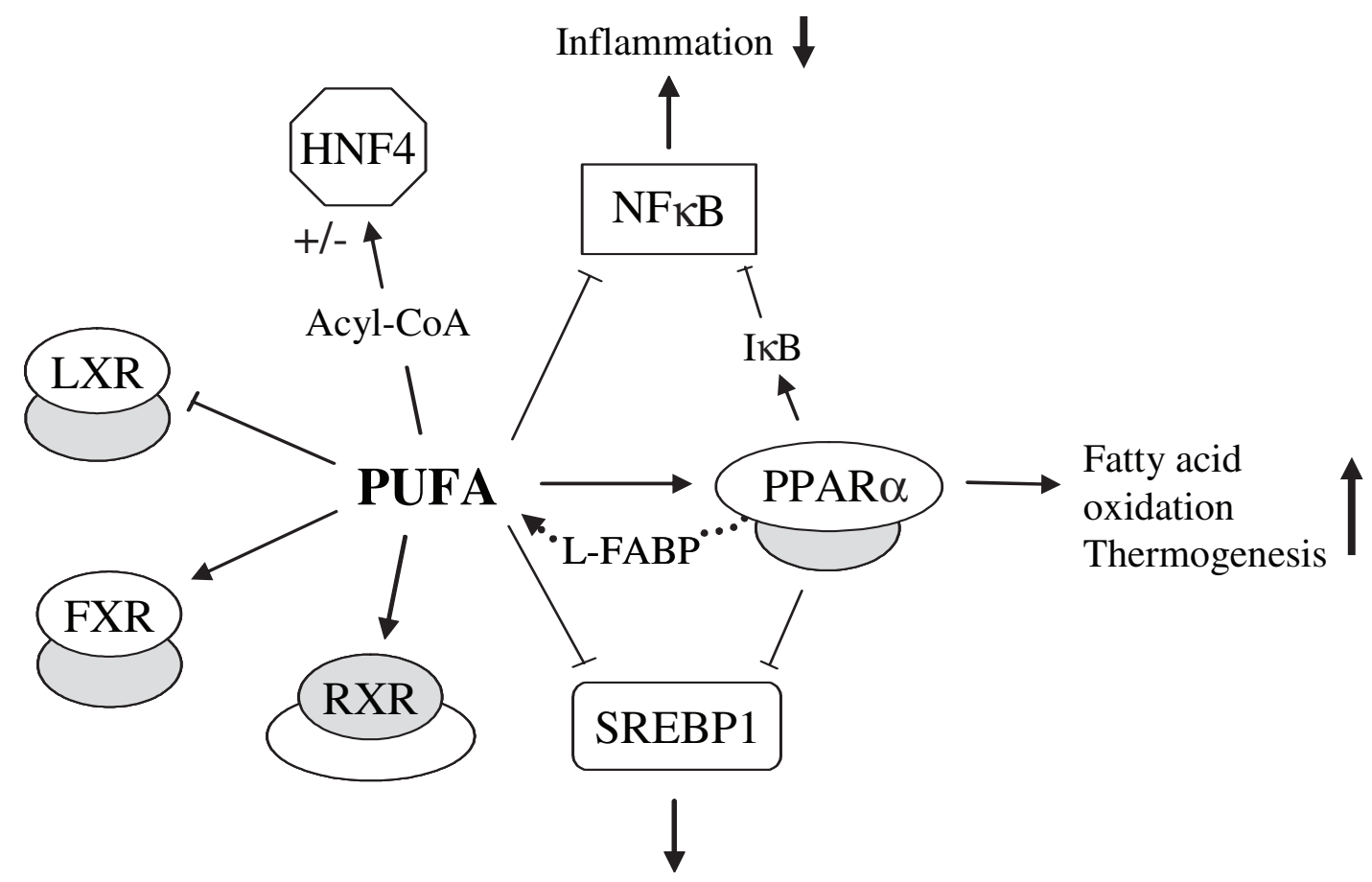

Fatty acid, Cholesterol synthesis

Figure 2

Transcription factors influenced by PUFA. PUFA can activate (PPAR $\alpha, R X R$ and FXR) or repress (SREBP1, LXR and NFKB) various transcription factors. L-FABP as PPAR-binding protein can transport and deliver PUFA to PPAR $\alpha$. HNF4 transactivation is repressed by PUFA and activated by PUFA-CoA ester. RXR is the dimerization partner for PPAR $\alpha, L X R$ and FXR and represents a PUFA-binding protein.

PPAR $\alpha$, peroxisome proliferator-activated receptor $\alpha$; RXR, retinoid X receptor; FXR, farnesoid X receptor; SREBP1, sterol regulatory

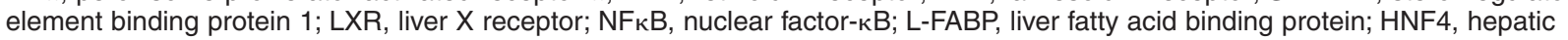
nuclear factor 4 (created from information in Schmitz and Ecker, 2008 and Dulpus et al., 2002). 
that are expressed at the onset of intestinal inflammation.

Methods for gene expression analysis that require the pre-selection of single genes, such as Northern blotting and quantitative PCR, are biased. These methods have been and are still useful, but they miss important effects on biological processes, such as metabolic and signalling pathways and transcriptional networks across several pathways (Subramanian et al., 2005).

DNA and oligonucleotide microarray technologies enable the analysis of genome-wide expression patterns (e.g. for particular diseases or physiological states) of organisms with a sequenced genome, allowing investigators to establish gene networks and identify new genes involved in the investigated trait. Gene expression profiling, or transcriptomics, is widely used in both biomedical (Subramanian et al., 2005) and nutrition (Müller and Kersten, 2003) research to characterize molecular- pathway and network data in a variety of tissues in laboratory animals (Langmann et al., 2004; Rivera et al., 2006; Dommels et al., 2007) and in response to dietary treatments to predict a phenotypic outcome (De Vogel-van den Bosch et al., 2008; Nones et al., 2008; Sanderson et al., 2008).

However, extracting the biological significance of a large amount of gene data is still a challenge. Information about genes is organized in ontologies, such as Gene Ontology (Prüfer et al., 2007). There are several tools for gene ontology enrichment analysis (Ingenuity pathway analysis or IPA, FUNC and many others) available to help interpret the extensive gene lists generated using transcriptomics.

IPA software has a manually created knowledge base and combines gene ontology enrichment with pathway enrichment analysis, network construction and comparison analysis. The biological interaction networks in IPA identify nodes (hub genes) that are central in connections between the differentially expressed genes. FUNC is also a useful tool to analyze large-scale gene expression data in the context of functional annotations (Prüfer et al., 2007). The disadvantage of the FUNC approach compared to that of IPA is that it does not incorporate a function or pathway analysis and lacks a disease focus.

Hub genes are validated by quantitative realtime PCR to confirm their expression as seen in microarrays. More importantly, their function and possible target genes can be further investigated through cell-based transactivation assays.

\subsection{Animal models of IBD}

Several in vitro studies have been carried out to investigate the effect of essential fatty acids on various cell cultures (Grammatikos et al., 1994). The current in vitro models are useful for screening food components, but they are unable to mimic the complexity of the intestinal tract. Thus in vivo models of IBD are important for unravelling the complex interactions between food, intestinal bacteria and intestinal cells and thus elucidating the mechanisms of initiation and progression of intestinal inflammation.

Many different animal models to study intestinal inflammation are available, including gene knockout or defect, transgenic, spontaneous colitis, inducible colitis and adoptive transfer models (Jurjus et al., 2004). These animal models display some of the key characteristics of intestinal inflammation (such as morphological changes, inflammation status and onset and progression of disease pathophysiology) and have a well-defined genetic background and immune system.

The animal models that have been widely used, and which will be covered in this review, are inducible colitis (chemicals, pathogenic bacteria) and genetic rodent models. Chemicals that are used to induce acute intestinal colitis include dextran sodium sulphate (DSS) and 2,4,6-trinitrobenzene sulfonic acid (TNBS) (Jurjus et al., 2004). Two examples of pathogenic bacteria that can induce intestinal lesions are enteroinvasive Escherichia coli or Salmonella typhimurium (Gill et al., 2001). The parameters commonly monitored in chemically- and pathogenic bacteria-induced colitis models are histological lesions and biochemical parameters such as myeloperoxidase activity, glutathione concentration and cytokine profiles.

Genetic mouse models with certain gene mutations and deficiencies such as the interleukin 10 gene deficient (IL10 ${ }^{-/}$) mouse (Kühn et al., 1993; Roy et al., 2007) and the multidrug resistance gene deficient (mdr1a ${ }^{-/}$) mouse (Dommels et al., 2007) show chronic and spontaneous intestinal inflammation. Some of these models which are commercially available have a single gene defect to induce a human IBD-like colitis. IL10 is an antiinflammatory cytokine and an IL10 gene defect causes an imbalance in the inflammatory responses. It has been reported that $\mathrm{IL} 10^{-/}$mice (C57BL/6J/129-Ola background) develop a Crohn's disease-like colitis by 12 weeks of age when raised under conventional conditions (Berget et al., 1996). The level of inflammation seen in IL $10^{-/-}$mice varies depending on the genetic background; intestinal lesions are least severe in the C57BL/6J strain (Berg et al., 1996). Thus, to induce a more consistent intestinal inflammation, IL $10^{-/-}$mice can be inoculated with Enterococcus faecalis (Balish and Warner, 2002) or pure Enterococcus isolates (E. faecalis and E. faecium) combined with a mixed "complex intestinal flora" derived from healthy C57BL/6J mice raised under conventional conditions (Roy et al., 2007). The exact mechanism of IBD pathogenesis, both in animal models and in humans, is still unclear. An inappropriate T helper 1 (Th1) response to antigens of the normal intestinal flora has been suggested due to the lack of IL10 that normally down-regulates such $\mathrm{T}$ cell reactivity (Kühn et al., 1993; Berg et al., 1996). 
Despite the IBD-like symptoms that develop in IL10 $0^{-1-}$ mice, IL10 gene variants have not consistently been found in IBD patients, whereas variants of the IL23 receptor have been, e.g., in the New Zealand population (Roberts et al., 2007). IL23 has been shown to regulate $T$ cell-mediated colitis in the IL10/- mice (Yen et al., 2006). The most common human IBD susceptibility gene is NOD2 (Ferguson et al., 2007, Torres and Ríos, 2008), and one common variant in this gene is a $\mathrm{C}$ insertion at position 3020 , which leads to a truncated gene product (NOD2 $\Delta 33$ ). The NOD2 $\Delta 33$ mouse develops colon inflammation and ulceration in response to microbial invasion (Maeda et al, 2005), because of a failure to differentiate between existing intestinal flora and invading bacteria.

\subsection{Inflammatory lesions and mediator production}

In this section, results from studies using animal models of IBD fed diets supplemented with PUFA are discussed, with particular emphasis on inflammatory lesion development as evaluated by histology, immunohistochemistry, lipid and protein mediator profiles and changes in intestinal gene expression.

Reviews of studies using dietary long chain PUFA (as fish oil) in IBD patients (Belluzzi, 2002; Calder, 2008) have concluded some benefits of fish oil including improvement of clinical score and gut mucosal histology and decreased relapse. Despite these beneficial effects of fish oil, there are also studies that report no effect on disease activity, higher rate of relapse or no effect on relapse with fish oil (Calder, 2008). Overall evidence of clinical benefits of n-3 PUFA in IBD is rather weak.

Only a few animal (Hansen Petrik et al., 2000) and human (Shimizu et al., 2003) studies have investigated the effects of purified PUFA in intestinal inflammation. The study of Hansen Petrik et al., (2000) evaluated the effect of purified AA and EPA ethyl ester alone and in combination on colorectal cancer using the $A p C^{\mathrm{Min} /+}$ mouse model. EPA could reduce the number and size of tumors associated with decreased tissue $\mathrm{AA}$ and prostaglandin levels, whereas AA supplementation to the EPA diet reduced anti-tumorigenic effect of EPA. The study of Shimizu et al., (2003) investigated the impact of highly purified EPA ethyl ester given daily for 2 months to children with $U C$ in relapse. $\mathrm{LTB}_{4}$ production from leukocytes and colon mucosa after 2 month of treatment was lower than before treatment. However, there was no control group without, so it is difficult to associate the absence of relapses for the study period with the EPA ethyl ester administration.

The animal studies summarized here mainly involve chemically-induced colitis models. The effects of dietary PUFA supplementation on disease severity are related to the production of proinflammatory eicosanoids. Four studies have found decreased colon or ileum damage and inflammation compared to $\mathrm{n}-6$ PUFA diet in a rat model of chemically-induced colitis (Vilaseca et al., 1990; Empey et al., 1991; Yuceyar et al., 1999; Nieto et al., 2002). Vilaseca et al., (1990) compared the effects of dietary supplementation with either sunflower (n-6) or cod liver (n-3) oil on the development of chronic granulomatous lesions in the colon of a TNBS rat model. Luminal eicosanoid levels increased after TNBS challenge in both groups. The eicosanoids $\mathrm{PGE}_{2}$ and $\mathrm{LTB}_{4}$ production declined after a few days, whereas the eicosanoid $\mathrm{TXB}_{2}$ continued to rise in the $\mathrm{n}-6$ diet group. In the n-3 group the colon lesions were markedly reduced after 30 days and inflammation, as well as ulceration, were almost absent by 50 days. The study concluded that the fish oil diet prevented the $\mathrm{TXB}_{2}$ increase in the chronic stage of inflammation. Further evidence for protective effects of a fish oil (EPA)-enriched diet is shown by histological improvements in colon and ileum mucosa of rats challenged with $4 \%$ acetic acid to induce colitis (Empey et al., 1991).

The therapeutic effects of n-3 PUFA on TNBSinduced colitis was also investigated in a rat model of CD (Shoda et al., 1995). The rats were fed a diet enriched with $2 \%$ n-3 PUFA-rich perilla oil and compared to a diet enriched with $2 \%$ n-6 PUFA-rich safflower oil. In rats from the n-3 PUFA group, plasma $\mathrm{LTB}_{4}$ concentrations and colon damage were reduced compared to those in the $n-6$ PUFA group. This study also suggested that supplementation with $2 \% n-3$ PUFA $\alpha$-linolenic acid, the precursor of EPA and DHA, may be more therapeutically efficient in controlling intestinal inflammation in experimental $C D$ than either EPA or DHA.

In a TNBS-induced rat colitis model, the protective role of fish oil ( $n-3$ PUFA) (both as an enriched diet, or administered intrarectally) was investigated (Yuceyar et al., 1999). The n-3 PUFA enriched diet showed a protective effect by decreasing production of $\mathrm{LTB}_{4}$ and $\mathrm{LTC}_{4}$, and by decreasing activity of the myeloperoxidase, an enzyme which is stored in granules of polymorphonuclear neutrophils and macrophages and released into extracellular fluid in the setting of inflammatory processes. In a study by Campos et al., (2002), parenteral lipid emulsions enriched with n-3 PUFA reduced diarrhea, attenuated morphological changes and decreased colon concentrations of inflammatory mediators in a rat model of acetic acid-induced colitis.

Nieto et al., (2002) studied biochemical and histological alterations in rats with TNBS-induced ulcerative colitis fed with mono- and/or polyunsaturated fatty acids (enriched with $\mathrm{n}-3$ and n-6 PUFA). The fish oil group showed less colon damage, lower alkaline phosphatase and myeloperoxidase activities and $\mathrm{PGE}_{2}$ levels compared to the olive oil group.

Another two studies have investigated the effect of $n-3$ PUFA diets on pro-inflammatory cytokine 
production (Andoh et al., 2003; Whiting et al., 2005). In the former, the effects of $n-3$ and $n-6$ PUFA-rich diets (fed for 12 days prior to the induction of enteritis by TNBS) on intestinal inflammation and modulation of early responses were evaluated in rats. Mucosal changes were more severe and serum IL6 levels higher in rats fed the n6 PUFA diet compared with those in the n-3 PUFA group, suggesting a possible suppression of mucosal inflammation by blockage of mucosal IL6 secretion, but no difference was seen in the TNF $\alpha$ levels between the diet groups. In the latter study (which used Severe Combined Immunodeficiency (SCID) mice fed n-3-enriched or control diet before colitis induction by transplantation of CD45RB ${ }^{\text {high }}$ $T$ cells), the transplanted n-3 PUFA fed animals showed reduced clinical colitis and colon immunopathology associated with decreasing proinflammatory cytokine synthesis (TNF $\alpha$, IL12, IL1 $\beta$ ). There was also reduced myeloid cell recruitment and activation, enhanced epithelial barrier function (epithelial ZO-1 protein, mucosal type I collagen) and induction of the mucosal wound healing mechanism (Whiting et al., 2005).

As is the case in human clinical trials, there are also conflicting results from studies with fish oil or PUFA-enriched diets using animal models of IBD. Models of chemically-induced acute colitis have primarily been used in these studies and have generally shown anti-inflammatory effects of fish oil (Hegazi et al., 2006). However, preliminary data in a DSS-induced mouse model of colitis (Ramakers et al., 2008) have shown that an AA-enriched (ethyl ester oil) diet increased colon AA content, but did not result in more colon inflammation compared with the fish oil (EPA/DHA) and oleic acid (sunflower seed oil) diet groups. The AA-enriched diet even exerted protective effects in colitis (reduced weight loss and diarrhea scores) than observed in the other two groups.

There are also conflicting data from studies using genetic models such as the $\mathrm{IL} 10^{-/}$mouse. $\mathrm{IL}_{10}{ }^{-1-}$ mice represent a model for Th1-mediated IBD that spontaneously develop colitis (Kühn et al., 1993). One study with IL $10^{-/-}$mice found that fish oil (n-3 PUFA-enriched) reduced colon inflammation compared to n-6 PUFA-rich corn oil (Chapkin et al., 2007). Another study reporting the effects of fish oil ( $n-3$ PUFA) and olive oil ( $n-9$ monounsaturated fatty acids) compared with control corn oil (n-6 PUFA) on the severity of chronic colitis in IL $10^{---}$mice studied COX2 expression as a possible mediator of the immunomodulatory effects of dietary fatty acids on chronic colitis (Hegazi et al., 2006). The fish oil diet, however, increased chronic colitis in the colon, and had inhibitory effects on intestinal COX2 expression. Inhibition of COX2 expression results in decreased production of anti-inflammatory eicosanoids, e.g. $\mathrm{PGE}_{2}$.

The pathogenesis of chemically induced colitis may be different compared to genetically induced colitis. Furthermore, the development of colitis in IL $10^{-/}$mice is in some studies dependent on the presence of commensal luminal bacteria. In particular, inoculation with pure isolates of Enterococcus species, either in isolation (Balish and Warner, 2002), or combined with a mixed "complex intestinal flora" derived from healthy control mice (Roy et al., 2007) appears to play a critical role in establishing consistent inflammation in the intestinal mucosa. It may be that some of the conflicting data in genetic mouse models could be due to variations in bacterial colonization of the gastrointestinal tract. Additional studies are therefore warranted to investigate the mechanisms of PUFA on intestinal bacteria, e.g. PUFA can affect mucosal adhesion sites for intestinal bacteria, and better characterize the role of bacteria in inflammation using genetic animal models of colitis.

The findings from previous rodent studies examining the effectiveness of $n-3$ and $n-6$ PUFA are inconsistent or conflicting. The discrepancy may be caused by confounding factors of the diet or PUFA supplements. Variation can arise from the study design, diets and feeding procedures, including impurity or unwanted oil components, flavour, sensitivity to oxidation, diet storage, duration of diet change etc., which can affect the n6/n-3 fatty acid ratio (Hudert et al., 2006).

Furthermore, because of the disparity in results from both chemically induced and genetic models of colitis, it is clear that further studies are necessary to elucidate differential effects of fatty acids on the time-course of colitis development.

\subsection{Intestinal gene expression}

Molecular targets for the protective actions of $n$ 3 and/or n-6 PUFA on experimental IBD models are yet to be elucidated. Only a few studies have investigated intestinal gene expression changes after PUFA supplementation in animal models of IBD using single gene approaches. Studies of the molecular mechanism underlying the PUFA effect from human studies are also lacking.

Caplan et al., (2001) found a reduction of necrotizing enterocolitis and intestinal inflammation in a neonatal rat model stressed with asphyxia (increases susceptibility to necrotizing enterocolitis) and fed with PUFA formula containing $A A$ and DHA. This study also revealed that PUFA reduced the intestinal mRNA expression of the platelet activating factor (PAF)-synthesizing enzyme PLA2 and the PAF receptor, a marker of intestinal inflammation. In similar studies, PUFA supplementation reduced the incidence of necrotizing enterocolitis and also inhibited intestinal PAF receptor and TLR4 gene expression compared with the controls in a rat model. The rats were fed AA/DHA, egg phospholipids or DHA only. All PUFA supplementations downregulated PAF receptor expression in ileum and colon, suggesting an interaction between the PAF receptor and TLR signalling as a possible mechanism for the protective effect of PUFA on intestinal injury (Lu et al., 2007). 
The effect of conjugated linoleic acid (CLA) and n-3 PUFA alone and in combination to prevent or ameliorate IBD in a pig model of DSS-induced colitis has been evaluated (Bassaganya-Riera and Hontecillas, 2006). Feeding CLA to the pigs delayed the onset of IBD, with less severe colitis and attenuated growth suppression which correlated with induction of colon PPAR $\gamma$, over-expression of PPAR $\gamma$-coactivator- $1 \alpha$ and down-regulation of TNF $\alpha$. n-3 PUFA supplementation alone or in a mixture with CLA resulted in an early disease onset because of a marked induction of the PPAR $\delta$-response gene uncoupling protein 3. CLA and n-3 PUFA synergistically up-regulated colon keratinocyte growth factor expression but n-3 PUFA blocked CLAinduced PPAR $y$ activation. In this pig study n-3 PUFA failed to protect from IBD but accelerated colon regeneration and clinical remission by activating PPAR $\delta$.

Another group has studied n-3 PUFA-derived lipid mediators in the fat-1 transgenic mouse with DSS-induced colitis (Hudert et al., 2006). These mice express the Caenorhabditis elegans fat- 1 gene encoding an n-3 fatty acid desaturase and thus are able to produce n-3 PUFA from n-6 PUFA. These mice had lower colon inflammation than wildtype mice, and this was associated with changes in n-3-derived anti-inflammatory mediators and a decrease in expression of genes involved in colon inflammation (NFKB, TNF $\alpha$, inducible NO synthase and IL1 $\beta$ ). Increased mRNA levels for genes important to membrane integrity, such as trefoil factor 3 , the intercellular tight junction protein zonula occludens 1 and Toll-interacting protein (an inhibitor of the Toll-like receptor pathway mediating inflammatory response) were also observed.

\section{CONCLUSIONS AND FUTURE PERSPECTIVES}

This review describes the complex interactions between dietary PUFA, inflammatory and immune responses and regulation of gene expression in order to provide an overview of the multi-factorial aetiology of IBD.

Many studies have focused on the antiinflammatory effects of n-3 PUFA as indicated by reports of histological assessments, circulating PUFA concentrations or ex vivo production of inflammatory mediators. A range of animal models of acute chemically-induced colitis show primarily antiinflammatory effects of fish oil rich in n-3 PUFA. The increased colitis associated with dietary fish oil suggests that the pathogenesis of spontaneous colitis may be different to chemically-induced colitis. Most of the animal studies reviewed here provided higher fat diets $(10 \%$ or more) compared to a normal laboratory rodent diet with $5 \%$ fat, and the use of fish oil means there was a mixture of various fatty acids present in these diets. Thus, any observed anti-inflammatory or immunomodulatory effects have been assigned to a fatty acid mix rather than pure PUFA.
Few animal studies of IBD have applied genome-wide expression profiling to define the molecular mechanisms underlying the diseasephenotype when PUFA diets are fed. Genome-wide studies use modern technologies and knowledge derived from the human genome project to provide a more comprehensive understanding of the multiple pathways by which PUFA can regulate transcriptional and metabolic processes.

A large part of the evidence regarding antiinflammatory and immunomodulatory effects of PUFA has arisen from cell culture studies where single fatty acids have been added. In order to define effects of dietary PUFA on IBD, animal model systems with diets of well defined fatty acid composition and purity would be advantageous. These studies should incorporate the "omics" tools (transcriptomics, proteomics, metabolomics) available to nutrition research. Translating these complex results represents a major challenge for nutrigenomics research. The genome-wide approach generates a huge amount of data with the potential to explore the biological importance of genes even beyond statistical significance. Once hub genes that are differentially expressed in response to PUFA have been identified by transcriptome analyses, other techniques (including chromatin immunoprecipitation and transactivation assays) can be applied in order to define direct targets of the PUFA-responding central genes.

\section{ACKNOWLEDGMENTS}

The authors would like to thank $\mathrm{Dr}$ Mark McCann (AgResearch) for proof-reading the manuscript.

\section{REFERENCES}

Andoh A, Tsujikawa T, Ishizuka I, Araki Y, Sasaki M, Koyama S, Fujiyama Y. 2003. N-3 fatty acid-rich diet prevents early response of interleukin-6 elevation in trinitrobenzene sulfonic acid-induced enteritis. Int. J. Mol. Med. 12, 721-725.

Balish E, Warner T. 2002. Enterococcus faecalis induces inflammatory bowel disease in interleukin-10 knockout mice. Am. J. Pathol. 160, 2253-2257.

Bannenberg G, Arita M, Serhan CN. 2007. Endogenous receptor agonists: resolving inflammation. The Scientific World Journal 7, 1440-1462.

Bassaganya-Riera, J, Hontecillas R. 2006. CLA and n-3 PUFA differentially modulate clinical activity and colonic PPAR-responsive gene expression in a pig model of experimental IBD. Clin. Nutr. 25, 454-465.

Belluzzi A. 2002. N-3 Fatty acids for the treatment of inflammatory bowel disease. Proc. Nutr. Soc. 61, 391395.

Berg DJ, Davidson N, Kühn R, Müller W, Menon S, Holland G, Thompson-Snipes L, Leach MW, Rennick D. 1996. Enterocolitis and colon cancer in interleukin10-deficient mice are associated with aberrant cytokine production and CD4+ TH1-like responses. J. Clin. Invest. 98, 1010-1020. 
Bünger M, Van Den Bosch HM, Van Der Meijde J, Kersten S, Hooiveld G, Müller M. 2007. Genome-wide analysis of PPAR alpha activation in murine small intestine. Physiol. Genomics 30, 192-204.

Calder PC. 2003. N-3 polyunsaturated fatty acids and inflammation: From molecular biology to the clinic. Lipids 38, 343-352.

Calder PC. 2006. N-3 polyunsaturated fatty acids, inflammation, and inflammatory diseases. Am. J. Clin. Nutr. 83, 1505S-1519S.

Calder PC. 2008. Polyunsaturated fatty acids, inflammatory processes and inflammatory bowel diseases. Mol. Nutr. Food Res. 52, 885-897.

Campos FG, Waitzberg DL, Habr-Gama A, Logullo AF, Noronha IL, Jancar S, Torrinhas RSM, Furst P. 2002. Impact of parenteral n-3 fatty acids on experimental acute colitis. Brit. J. Nutr. 87, S83-S88.

Caplan MS, Russell T, Xiao Y, Amer M, Kaup S, Jilling, T. 2001. Effect of polyunsaturated fatty acid (PUFA) supplementation on intestinal inflammation and necrotizing enterocolitis (NEC) in a neonatal rat model. Pediatr. Res. 49, 647-652.

Chapkin RS, Davidson LA, Ly L, Weeks BR, Lupton JR, McMurray DN. 2007. Immunomodulatory effects of (n3) fatty acids: Putative link to inflammation and colon cancer. J. Nutr. 137, 200S-204S.

De Vogel-Van Den Bosch HM, Bünger M, De Groot PJ, Bosch-Vermeulen H, Hooiveld GJEJ, Müller M. 2008. PPARalpha-mediated effects of dietary lipids on intestinal barrier gene expression. BMC Genomics 9, 231.

Deckelbaum RJ, Worgall TS, Seo T. 2006. N-3 fatty acids and gene expression. Am. J. Clin. Nutr. 83, 1520S1525S.

Dommels YEM, Alink GM, Van Bladeren PJ, Van Ommen B. 2002. Dietary $n-6$ and $n-3$ polyunsaturated fatty acids and colorectal carcinogenesis: results from cultured colon cells, animal models and human studies. Environ Toxicol Pharmacol. 12, 233-244.

Dommels EM, Butts CA, Zhu S, Davy M, Martell S, Hedderley D, Barnett MPG, McNabb WC, Roy NC. 2007. Characterization of intestinal inflammation and identification of related gene expression changes in mdr1a $^{-/}$mice. Genes Nutr. 2, 209-223.

Dulpus E, Glorian M, Forest C. 2000. Fatty acid regulation of gene transcription. J. Biol. Chem. 275, 3074930752.

Empey LR, Jewell LD, Garg ML, Thomson AB, Clandidin MT, Fedorak RN. 1991. Fish-oil enriched diet is mucosal protective against acetic acid-induced colitis in rats Can. J. Physiol. Pharm. 69, 480-487.

Ewaschuk JB, Dieleman LA. 2006. Probiotics and prebiotics in chronic inflammatory bowel diseases. World J. Gastroenterol. 12, 5941-5950.

Favier C, Neut C, Mizon C, Cortot A, Colombel JF, Mizon J. 1997. Fecal beta-D-galactosidase production and Bifidobacteria are decreased in Crohn's disease. Dig. Dis. Sci. 42, 817-822.

Ferguson LR, Shelling AN, Browning BL, Huebner C, Petermann I. 2007. Genes, diet and inflammatory bowel disease. Mutat. Res. 622, 70-83.

Geerling BJ, Van Houwelingen AC, Badart-Smook A, Stockbrugger RW, Brummer JM. 1999. Fat intake and fatty acid profile in plasma phospholipids and adipose tissue in patients with Crohn's disease, compared with controls. Am. J. Gastroenterol. 94, 410-417.

Gill HS, Shu Q, Lin H, Rutherfurd KJ, Cross ML. 2001. Protection against translocating Salmonella typhimurium infection in mice by feeding the immuno- enhancing probiotic Lactobacillus rhamnosus strain HN001. Med. Microbiol. Immunol. 190, 97-104.

Goodwin JS, Ceuppens J. 1983. Regulation of the immune-response by prostaglandins. J. Clin. Immunol 3, 295-315.

Goudriaan JR, Dahlmans VEH, Febbraio M, Teusink B, Romijn JA, Havekes LM, Voshol PJ. 2002. Intestinal lipid absorption is not affected in CD36 deficient mice. Mol. Cell. Biochem. 239, 199-202.

Grammatikos SI, Subbaiah PV, Victor TA, Miller WM. 1994. Diverse effects of essential (n-6 and n-3) fatty acids on cultured cells. Cytotechnology 15, 31-50.

Hansen Petrik MB, McEntee MF, Chiu CH, Whelan J. 2000. Antagonism of arachidonic acid is linked to the antitumorigenic effect of dietary eicosapentaenoic acid in $\mathrm{Apc}^{\mathrm{Min} /+}$ mice. J. Nutr. 130, 1153-1158.

Hegazi RAF, Saad RS, Mady H, Matarese LE, O'keefe S, Kandil HM. 2006. Dietary fatty acids modulate chronic colitis, colitis-associated colon neoplasia and COX-2 expression in IL-10 knockout mice. Nutrition 22, 275282.

Heimerl S, Moehle C, Zahn A, Boettcher A, Stremmel W, Langmann T, Schmitz G. 2006. Alterations in intestinal fatty acid metabolism in inflammatory bowel disease. Biochim. Biophys. Acta-Mol. Basis Dis. 1762, 341350.

Hudert CA, Weylandt KH, Lu Y, Wang JD, Hong S, Dignass A, Serhan CN, Kang JX. 2006. Transgenic mice rich in endogenous omega-3 fatty acids are protected from colitis. Proc. Natl. Acad. Sci. U. S. A. 103, 11276-11281.

Jurjus AR, Khoury NH, Reimund JM. 2004. Animal models of inflammatory bowel disease. J. Pharmacol. Toxicol. Methods 50, 81-92.

Kankaanpää PE, Salminen SJ, Isolauri E, Lee YK. 2001. The influence of polyunsaturated fatty acids on probiotic growth and adhesion. FEMS Microbiol. Lett. 194, 149-153.

Kühn R, Löhler J, Rennick D, Rajewsky K, Müller W. 1993. Interleukin-10-deficient mice develop chronic enterocolitis. Cell 75, 263-274.

Kuroki F, lida M, Matsumoto T, Aoyagi K, Kanamoto K, Fujishima M. 1997. Serum n-3 polyunsaturated fatty acids are depleted in Crohn's disease. Dig. Dis. Sci. 42, 1137-1141.

Kussmann M, Raymond F, Affolter M. 2006. OMICSdriven biomarker discovery in nutrition and health. $J$. Biotechnol. 124, 758-787.

Langmann T, Moehle C, Mauerer R, Scharl M, Liebisch G, Zahn A, Stremmel W, Schmitz G. 2004. Loss of detoxification in inflammatory bowel disease: Dysregulation of pregnane $\mathrm{X}$ receptor target genes. Gastroenterol. 127, 26-40.

Lu J, Jilling T, Li D, Caplan MS. 2007. Polyunsaturated fatty acid supplementation alters proinflammatory gene expression and reduces the incidence of necrotizing enterocolitis in a neonatal rat model. Pediatr. Res. 61, 427-432.

Maeda S, Hsu LC, Liu H, Bankston LA, limura M, Kagnoff MF, Eckmann L, Karin M. 2005. Nod2 mutation in Crohn's disease potentiates NF-kappaB activity and IL-1 beta processing. Science 307, 734-738.

Mills SC, Windsor AC, Knight SC. 2005. The potential interactions between polyunsaturated fatty acids and colonic inflammatory processes. Clin. Exp. Immunol 142, 216-228

Mitsuyama K, Suzuki A, Tomiyasu N, Takaki K, Toyonaga A, Sata M. 2001. Transcription factor-targeted 
therapies in inflammatory bowel disease. Digestion 63, 68-72.

Müller M, Kersten S. 2003. Nutrigenomics: goals and strategies. Nat. Rev. Genet 4, 315-322.

Mutch DM, Grigorov M, Berger A, Fay LB, Roberts MA, Watkins SM, Williamson G, German JB. 2005. An integrative metabolism approach identifies stearoylCOA desaturase as a target for an arachidonateenriched diet. FASEB J. 19, 599-601.

Niess JH, Reinecker HC. 2006. Dendritic cells: the commanders-in-chief of mucosal immune defenses. Curr. Opin. Gastroenterol. 22, 354-360.

Nieto N, Torres MI, Rios A, Gil A. 2002. Dietary polyunsaturated fatty acids improve histological and biochemical alterations in rats with experimental ulcerative colitis. J. Nutr. 132, 11-19.

Nones K, Dommels YEM, Martell S, Butts C, McNabb WC, Park ZA, Zhu S, Hedderley D, Barnett MPG, Roy NC. 2008. The effects of dietary curcumin and rutin on colonic inflammation and gene expression in multiple drug resistance gene-deficient $\left(\mathrm{mdr} 1 \mathrm{a}^{-/-}\right)$mice, a model of inflammatory bowel diseases. Brit. J. Nutr. Sep2 (ahead of publication), 1-13.

Podolsky DK. 2002. Inflammatory bowel disease. N. Engl. J. Med. 347, 417-429.

Prüfer K, Muetzel B, Do HH, Weiss G, Khaitovich P, Rahm E, Pääbo S, Lachmann M, Enard W. 2007. FUNC: a package for detecting significant associations between gene sets and ontological annotations. BMC Bioinformatics 8, 41.

Ramakers JD, Mensink RP, Verstege MI, Te Velde AA, Plat, J. 2008. An arachidonic acid-enriched diet does not result in more colonic inflammation as compared with fish oil- or oleic acid-enriched diets in mice with experimental colitis. Brit. J. Nutr. 100, 347-354.

Rivera E, Flores I, Rivera E, Appleyard CB. 2006. Molecular profiling of a rat model of colitis: Validation of known inflammatory genes and identification of novel disease-associated targets. Inflamm. Bowel Dis. 12, 950-966.

Roberts RL, Gearry RB, Hollis-Moffatt JE, Miller AL, Reid J, Abkevich V, Timms KM, Gutin A, Lanchbury JS, Merriman TR, Barclay ML, Kennedy MA. 2007. IL23R R381Q and ATG16L1 T300A are strongly associated with Crohn's disease in a study of New Zealand Caucasians with inflammatory bowel disease. Am. J. Gastroenterol. 102, 2754-61.

Roy N, Barnett M, Knoch B, Dommels Y, McNabb W. 2007. Nutrigenomics applied to an animal model of inflammatory bowel diseases: Transcriptomic analysis of the effects of eicosapentaenoic acid and arachidonic acid-enriched diets. Mutat. Res.: Fundam. Mol. Mech. Mutagen 622, 103-116.

Salter A, Tarling E. 2007. Regulation of gene transcription by fatty acids. Animal 1, 1314-1320.

Sampath H, Ntambi J. M. 2005. Polyunsaturated fatty acid regulation of genes of lipid metabolism. Annu. Rev. Nutr. 25, 317-340.

Sanderson LM, De Groot PJ, Hooiveld GJEJ, Koppen A, Kalkhoven E, Müller M, Kersten S. 2008. Effect of synthetic dietary triglycerides: A novel research paradigm for nutrigenomics. PLOS ONE 3, e1681.

Schmitz G, Ecker J. 2008. The opposing effects of n-3 and n-6 fatty acids. Prog. Lipid Res. 47, 147-155.

Sellon RK, Tonkonogy S, Schultz M, Dieleman LA, Grenther W, Balish E, Rennick DM, Sartor RB. 1998. Resident enteric bacteria are necessary for development of spontaneous colitis and immune system activation in interleukin-10-deficient mice. Infect. Immun. 66, 5224-5231.

Serhan CN, Chiang N. 2008. Endogenous pro-resolving and anti-inflammatory lipid mediators: a new pharmacologic genus. Brit. J. Pharmacol. 153, S200S215.

Sheehan AL, Warren BF, Gear MWL, Shepherd NA. 1992. Fat-wrapping in Crohn's disease - Pathological basis and relevance to surgical practice. Brit. J. Surg. 79, 955-958.

Shimizu T, Fujii T, Suzuki R, Igarashi J, Ohtsuka Y, Nagata S, Yamashiro Y. 2003. Effects of highly purified eicosapentaenoic acid on erythrocyte fatty acid composition and leukocyte and colonic mucosa leukotriene B4 production in children with ulcerative colitis. J. Pediatr. Gastroenterol. Nutr. 37, 581-585.

Shoda R, Matsueda K, Yamato S, Umeda N. 1995. Therapeutic Efficacy of $n-3$ polyunsaturated fatty-acid in experimental Crohn's disease. J. Gastroenterol. 30, 98-101.

Simopoulos AP. 2002. Omega-3 fatty acids in inflammation and autoimmune diseases. J. Am. Coll. Nutr. 21, 495 - 505.

Soupene E, Kuypers FA. 2008. Mammalian long-chain Acyl-CoA synthetases. Exp. Biol. Med. 233, 507-521.

Stahl A. 2004. A current review of fatty acid transport proteins (SLC27). Pflueg. Arch. Eur. J. Physiol 447, 722-727.

Stulnig TM. 2003. Immunomodulation by polyunsaturated fatty acids: Mechanisms and effects. Int. Arch. Allergy Immunol. 132, 310-321.

Subramanian A, Tamayo P, Mootha VK, Mukherjee S, Ebert BL, Gillette MA, Paulovich A, Pomeroy SL, Golub TR, Lander ES, Mesirov JP. 2005. Gene set enrichment analysis: A knowledge-based approach for interpreting genome-wide expression profiles. Proc. Natl. Acad. Sci. U. S. A 102, 15545-15550.

Taurog JD, Richardson JA, Croft JT, Simmons WA, Zhou M, Fernandezsueiro JL, Balish E, Hammer RE. 1994. The germ-free state prevents development of gut and joint inflammatory disease in Hla-B27 transgenic rats. J. Exp. Med. 180, 2359-2364.

Torres MI, Ríos A. 2008. Current view of the immunopathogenesis in inflammatory bowel disease and its implications for therapy. World J. Gastroenterol. 14, 1972-1980.

Vilaseca J, Salas A, Guarner F, Rodriguez R, Martinez M, Malagelada JR. 1990. Dietary fish oil reduces progression of chronic inflammatory lesions in a rat model of granulomatous colitis. Gut 31, 539-544.

Whiting CV, Bland PW, Tarlton JE. 2005. Dietary n-3 polyunsaturated fatty acids reduce disease and colonic proinflammatory cytokines in a mouse model of colitis. Inflamm. Bowel Dis. 11, 340-349.

Wiercinska-Drapalo A, Jaroszewicz J, Siwak E, Pogorzelska J, Prokopowicz D. 2008. Intestinal fatty acid binding protein (I-FABP) as a possible biomarker of ileitis in patients with ulcerative colitis. Regul. Pept. 147, 25-28.

Wu TC. 2007. The role of vascular cell adhesion molecule-1 in tumor immune evasion. Cancer Res. 67, 6003-6006.

Yen D, Cheung J, Scheerens H, Poulet F, McClanahan T, Mckenzie B, Kleinschek MA, Owyang A, Mattson J, Blumenschein W, Murphy E, Sathe M, Cua DJ, Kastelein RA, Rennick D. 2006. IL-23 is essential for T cell-mediated colitis and promotes inflammation via IL-17 and IL-6. J. Clin. Invest. 116, 1310-1316. 
Yuceyar H, Ozutemiz O, Huseyinov A, Saruc M, Alkanat M, Bor S, Coker I, Batur Y. 1999. Is administration of n-3 fatty acids by mucosal enema protective against trinitrobenzene-induced colitis in rats? Prostaglandins Leukot. Essent. Fatty Acids 61, 339-345.

Recibido: 4/8/08 Aceptado: 1/9/08 